\title{
Modified Self-Expanding Plastic Stent for the Treat- ment of Refractory Benign Esophageal Strictures
}

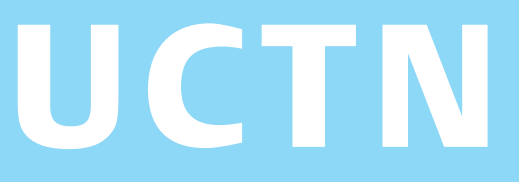

Self-expanding plastic stents (SEPSs) are increasingly used for the treatment of benign gastrointestinal strictures, because they may be extracted with substantially less tissue damage compared with selfexpanding metal stents. However, the problem of a high rate of premature dislocation is still unsolved, especially in strictures where there is also extended prestenotic or poststenotic dilatation, or both. Acutely waisted SEPS, which are so far not available, are required to stent these strictures.

To obtain such a stents we combine a colorectal SEPS (Polyflex, diameter 34/ 30/34mm, length $100 \mathrm{~mm}$; Rüsch, Kernen, Germany) with part of an esophageal SEPS (Polyflex, diameter 16/20 mm; Rüsch). The latter is shortened according to the length of the stricture and is then slipped over the colorectal stent like a napkin ring (Figure $\mathbf{1}$ ). The two parts are fixed together with a single nonresorbable suture. This combined colorectalesophageal stent can be inserted using the original introducing system for the colorectal SEPS.

Figure 2 shows the application of the stent described above, in a 12-year-old girl with a megaesophagus caused by a $3-\mathrm{cm}$ stricture of the esophagocardial junction. This stricture was the result of a a failed antireflux surgical procedure, and treatment with bougienage and balloon dilation had been unsuccessful. All the available esophageal Polyflex stents, up to the largest diameter $(21 / 25 \mathrm{~mm})$, had migrated within a few days. In contrast, our modified Polyflex stent stayed in the correct place for 4 weeks.

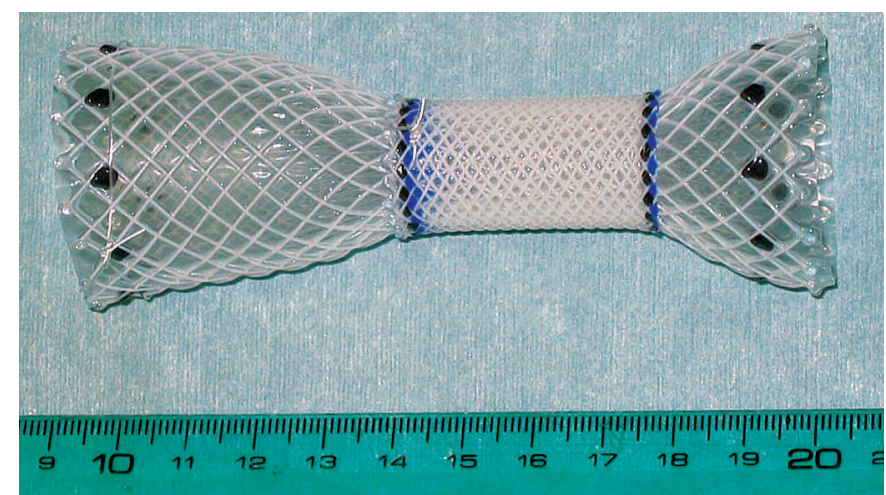

Figure 1 Construction of the modified self-expanding plastic stent (SEPS).
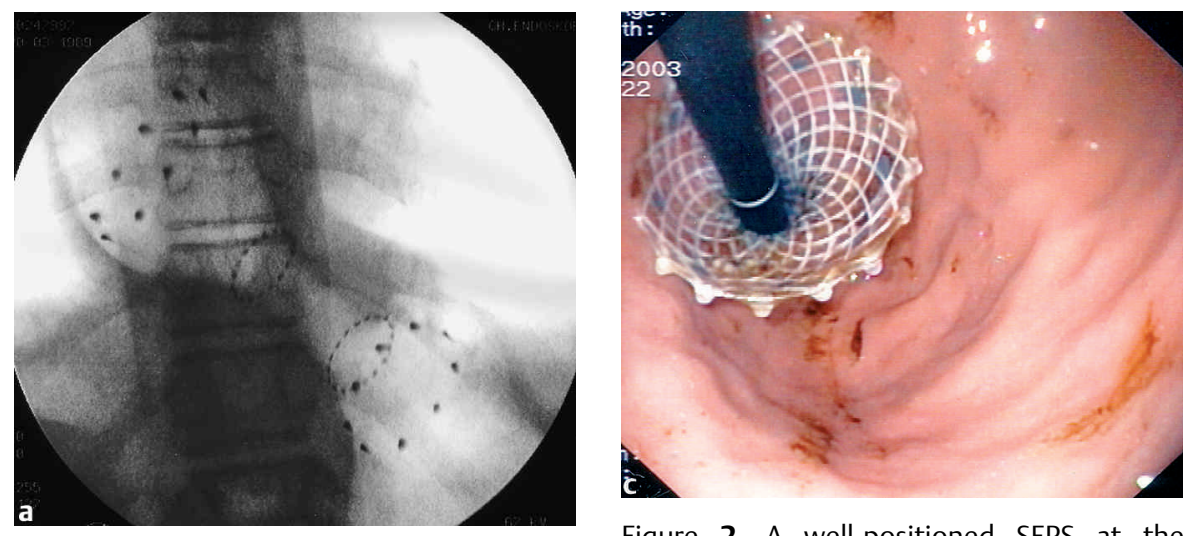

Figure 2 A well-positioned SEPS at the

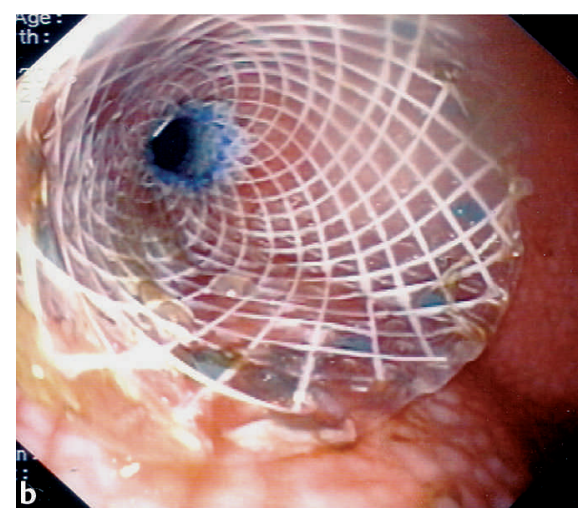

esophagocardial junction: a radiographic view; b prograde endoscopic view; c retrograde endoscopic view.

\section{Corresponding Author}

\section{A. Müldner, M.D.}

Sektion Endoskopie und Sonografie der Chirurgischen Klinik Universitätsklinikum Mannheim 68135 Mannheim

\section{Germany}

Fax: $\quad+49-6201-3833825$

E-mail: endoskopie@chir.ma.uni-

A. Müldner, K. Reinshagen,

M. Wüstner, G. Kähler

heidelberg.de

Division of Endoscopy and Sonography,

Department of Surgery,

Universitätsklinikum Mannheim,

Mannheim Germany 